\title{
Implementation of Quasi-Static Time Series Simulations for Analysis of the Impact of Electric Vehicles on the Grid
}

\author{
Cyril Allenspach, Reto Högger, Artjoms Obushevs, Petr Korba \\ Institute of Energy Systems and Fluid Engineering \\ Zurich University of Applied Science \\ Winterthur, Switzerland \\ obus@zhaw.ch,korb@zhaw.ch
}

\author{
Helen Reist \\ Stadtwerk Winterthur \\ Winterthur, Switzerland \\ Helen.Reist@win.ch
}

\begin{abstract}
In this paper, symmetrical electric vehicle charging impacts in existing low-voltage distribution grid are investigated throughout proposed methodology and their results analysed. Symmetrical loading- and voltage-related impacts are assessed for the extensive grid. A synthetic EV mix pattern was used with the purpose to demonstrate a universal observation of charging impacts. These patterns were allocated quasi-randomly to the points of common coupling within the grid based on predefined scenarios $-8,10,12$ and 20 percent. Subsequently, quasi-static time series simulations for a duration of one year in 10-minute time steps were executed. Consequently, this paper yields results, which offer practical insight in the maximum share of electric vehicle charging in low-voltage distribution grids and provide guidance for future decision-making of distribution grid operators.
\end{abstract}

Keywords-distribution system impacts, electric vehicles, power distribution, power system modeling, quasi-static time-series analysis

\section{INTRODUCTION}

Due to long-term transport policies, many countries have been installing new government programmes in recent years, the aim of which is to increase the number of parks for electric vehicles (EV) with close to zero emissions and develop infrastructures for servicing such vehicles [1]. Furthermore, the EU policies of reducing greenhouse gas emissions, especially the strategy Transport 2050, show a similarly ambitious target and framework for 2050. Their goal is to reduce the use of conventionally-fuelled cars in urban transport by $50 \%$ until 2030 and to phase out the mentioned car technology in cities by 2050 [2]. Although in Switzerland, the percentage of EV on the total car market is still insignificant with $3.3 \%$ in 2018 [3], due to the revision of the Swiss CO2-law - which will inure in 2021 - a strong growth of the electric mobility may happen [4]. In addition to the strategies and laws set, amplifying economic factors, such as the growing selection of EV models, especially by major car manufacturers (e.g. VW) [5], are supporting the expansion of electric mobility. In recent years, a progressive growth in the number of EV sales has taken place [6]. Essentially, it increases the demand for electricity and will prompt the profiles of peak daily load curve to change, which will affect the operation of local distribution networks [7]. Additionally, due to the local voltage changes, which are resulting from the accumulation of decentralised power generation equipment and the increasing number of $\mathrm{EV}$, the low-voltage grids are being pushed to their limits at increasing intervals [8]. Subsequently, the growing variations of load and production peaks, which are the source of the voltage changes, can entail repercussions on the entirety of the local grid [9]. Consequently, in the near future, if no adjustments to the current low-voltage distribution grids will be made, it is likely that the limitations of voltage deviation will exceed limits, protection devices will be tripped or else an overloading of cable lines occurs.

In this paper, symmetrical electric vehicle charging impacts in existing low-voltage distribution grid (LVDG) of the City of Winterthur are investigated throughout proposed methodology and the software DIgSILENT PowerFactory and their results analysed. In detail, symmetrical loading- and voltage-related impacts are assessed for the extensive grid. A synthetic EV mix pattern was used with the purpose to demonstrate a universal observation of charging impacts. Later, these patterns were allocated quasi-randomly to the points of common coupling within the grid based on predefined scenarios $-8,10,12$ and 20. Subsequently, quasi-static time series simulations for duration of one year in 10-minute time steps were executed. Consequently, this paper yields results, which offer practical insight in the maximum share of electric vehicle charging $(11 \mathrm{~kW})$ in low-voltage distribution grids and provide guidance for future decision-making of Swiss distribution grid operators such as Stadtwerk Winterthur (SW) [10].

Work structure is following. In the second chapter, the necessary fundamental information of the work is listed. The limitations of standards for electrical quantities of the distribution networks are presented, and comprehensive information on load flow calculations is provided. Third chapter presents and visualises the raw data utilised, the data adjustments made, and the simulation process. The assumptions for the creation of the extensive grid without EV charging are presented, and the distribution of the synthetic electric vehicle mix pattern is described. Fourth chapter provide information about extensive grid and input information definition. In fifth chapter, the voltage and loading results of the simulations for different scenarios of the LVDG are visualised and probable impacts analysed. In the final chapter, the interpretation of the results and a discussion of the identified impacts of EV charging on the specific networks are propounded and elucidated. 


\section{THEORETICAL PRINCIPLES}

To safely conform to the EN 50160 [11] voltage variation limits $- \pm 10 \%$ - and additionally, to stay within defined limits not only at the PCC, but even up to the power outlet of the consumer, Stadtwerk Winterthur defines an internal guideline value of $\pm 6 \%$ based on D-A-CH-CZ Rules [12] and are visualised in Figure 1.

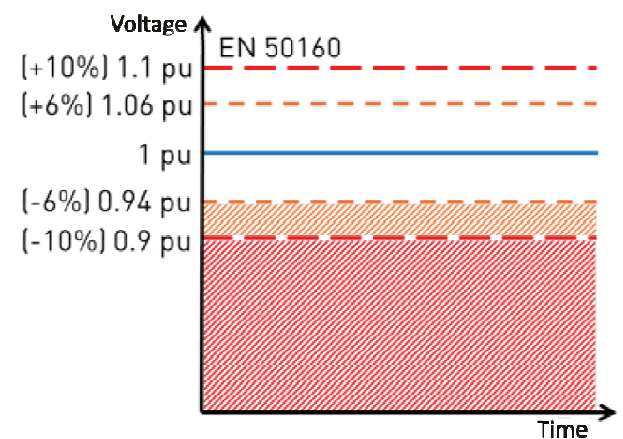

Fig. 1. Voltage threshold according to EN 50160 including voltage gap of warning defined by Stadtwerk Winterthur

Due to the previously mentioned internal definition, in this paper, the value of $\pm 6 \%$ is seen as a tightening of limitations and therefore, it is described in the analysis in addition to the EN 50160 limits.

\section{A. Quasi-Static Time Series Simulation}

In general, the Quasi-Static Time Series simulation is multiple load flow calculations, which are performed in succession to simulate time-dependent characteristics. Furthermore, when performing daily or yearly simulations, the solution at the present time step is used as the starting point for the solution in the next iteration. Unless there is a significant alternation of loading, the solution will typically converge considerably faster, when compared to the previously mentioned "flat start" approach. In essence, the first guess is often sufficient for the next iteration in simulations such as the Quasi-Static Time Series simulations at small intervals. As a consequence, almost half the computational effort can be saved in lengthy and elaborate simulations with a small-time step.

\section{B. Distinction to Quasi-Dynamic Simulation}

In this work, the quasi-static time series simulations for the analysis of the impact of electric vehicles on the grid were performed with the "Quasi-Dynamic Simulations" (QDS) PowerFactory-application. Loads within the LVDG were assigned individual, time-based characteristics such as EV charging pattern and Standard Load Profiles (SLP). The performed QDS covered the period of one year with a step size of 10 minutes and linear interpolations. No applications of control actions such as voltage regulation or load adjustment were executed during the QDS. Therefore, the so-called "Quasi-Dynamic" nature of the simulation method is rather a "Quasi-Static" nature.

\section{APPROACH AND METHODOLOGY}

\section{A. Standard Load Profiles}

Throughout the simulations - when consumer load profiles were required - the VDEW SLP [13] of the German
Association of Energy and Water Industries (BDEW) [14] for the year 2019 were applied. These SLP are standardised to yearly energy consumption of $1000 \mathrm{kWh}$. These load patterns display the typical loading pattern of a consumer-class in 15 min timesteps for the entirety of the calendar year. Consequentially the mentioned SLP can be used as a representative estimation of typical consumer load patterns.

In order to modify the normalised SLP, a yearly referenceconsumption can be defined, from which a consumer characteristic load pattern can be derived. Two alternatives are listed below to scale the VDEW SLP according to the given input information:

- Given yearly energy consumption:

Equation (1) describes how the proportion of the yearly energy consumption input $E_{\text {input }}$ and the integrated energy consumption of the SLP - which is normalised to $1000 \mathrm{kWh}-$ define the current active power at a time $t_{i}$ :

$$
P\left(t_{i}\right)=p\left(t_{i}\right)_{V D E W_{-} S L P} \times \frac{E_{\text {input }}}{\sum p\left(t_{i}\right)_{V D E W_{-} S L P} \times \bullet}
$$

Where:

$$
\begin{array}{ll}
P\left(t_{i}\right) & \text { Current active power [kW] } \\
E_{\text {input }} & \text { Yearly energy consumption [kWh] } \\
p\left(t_{i}\right)_{\text {VDEW_SLP }} & \text { Value of SLP at the time } t_{i}[\mathrm{~kW}] \\
\bullet t & \text { SLP time step in 15 min [min] } \\
\text { - } & \text { Given consumer maximum power: }
\end{array}
$$

Alternatively, if only the maximum power $P_{\max }$ of the consumers' consumption is known, the SLP can be scaled as described in Equation (2):

$$
P\left(t_{i}\right)=\frac{p\left(t_{i}\right)_{V D E W_{-} S L P}}{\max \left(p\left(t_{i}\right)_{V D E W_{-} S L P}\right)} \times P_{\text {max }_{-} \text {consumer }}
$$

Where:

$$
\begin{array}{ll}
\max \left(p\left(t_{i}\right)\right) & \text { Maximum load throughout the SLP }[\mathrm{kW}] \\
P_{\text {max_consumer }} & \text { Maximum consumer Load }[\mathrm{kW}]
\end{array}
$$

Furthermore, a power factor of 0.9 was assumed for the "Residual Grid"-load.

\section{B. EV Charging Category}

The European standard charging categories described in Table I were considered as a guideline for the EV-Mix generation, which is described in this section. In this work, a customised charging level, respectively charging characteristic was applied for the synthetical EV-Mix. The crucial background, which lead to decision of using a customised charging level, was given by the data provided by SW, which were the following:

- Various residential grid consumer with relatively small service lines of e.g. 25 A limitation

- EV charging stations of $11 \mathrm{~kW}$ installed at SW.

Therefore, a customised "three-phased Level 1" charging category was defined (see Table II). 
TABLE I. CHARGING CHARACTERISTICS BY IEC 61851 CATEGORIES IN EUROPE [15]

\begin{tabular}{|c|c|c|c|c|c|}
\hline $\begin{array}{c}\text { Charging } \\
\text { Level }\end{array}$ & Connection & $\begin{array}{c}\text { Power } \\
{[\mathrm{kW}]}\end{array}$ & $\begin{array}{c}\text { Voltage } \\
{[\mathrm{V}]}\end{array}$ & $\begin{array}{c}\text { Current } \\
{[\mathrm{A}]}\end{array}$ & Typical Usage \\
\hline Level 1 & 1-Phase AC & $<3.7$ & 230 & $\leq 16$ & $\begin{array}{c}\text { Primarily } \\
\text { domestic }\end{array}$ \\
\hline Level 2 & $\begin{array}{c}\text { 1- or 3- } \\
\text { Phase AC }\end{array}$ & $<22$ & $230 / 400$ & $\leq 32$ & $\begin{array}{c}\text { Domestic, } \\
\text { workplace, } \\
\text { public }\end{array}$ \\
\hline Level 3 & 3-Phase AC & $\leq 120$ & 400 & $\leq 250$ & $\begin{array}{c}\text { Commercial } \\
\text { publicly }\end{array}$ \\
\hline $\begin{array}{c}\text { DC Rapid } \\
\text { Charge }\end{array}$ & $\begin{array}{c}\text { DC } \\
\text { Connection }\end{array}$ & $\leq 120$ & $\mathrm{n} / \mathrm{a}$ & $\leq 400$ & $\begin{array}{c}\text { Commercial } \\
\text { publicly }\end{array}$ \\
\hline
\end{tabular}

TABLE II. CUSTOMISED CHARGING LEVEL KEY PARAMETERS

\begin{tabular}{|c|c|c|c|}
\hline $\begin{array}{c}\text { Supported Phase- } \\
\text { Configuration }\end{array}$ & $\begin{array}{c}\text { Supported Phase } \\
\text { Current }[\mathrm{A}]\end{array}$ & $\begin{array}{c}\text { Supported Phase } \\
\text { Power }[\mathrm{kW}]\end{array}$ & $\begin{array}{c}\text { Total Supported } \\
\text { Power }[\mathrm{kW}]\end{array}$ \\
\hline $\begin{array}{c}\text { Three- } \\
\text { phase }(3 \times 230 \mathrm{~V})\end{array}$ & $\leq 16$ & $\leq 3.7$ & $\leq 11$ \\
\hline
\end{tabular}

\section{Synthetic EV-Mix Charging Pattern}

The original charging data of several EV was provided by SW and obtained by PQ measurements. For the simulation, a synthetic EV-Mix charging pattern was created using the maximum power measurements of the individual models.

Three EV charging pattern for three different models were utilised, which are listed in Table 1 . Furthermore, with the numerical integration of the charging loads during the charging process, the respective battery capacities were determined. The EV models and their determined energy contents are shown in Table 1.

TABLE III. EV MODELS WITH A DETERMINED BATTERY CAPACITY

\begin{tabular}{|c|c|}
\hline Name & Energy content [kWh] \\
\hline BMW i3 94 Ah & 33 \\
\hline Renault Zoe & 41 \\
\hline Tesla Model S 85D & 85 \\
\hline
\end{tabular}

Based on the individual sales of the three mentioned EV models in Switzerland from October 2017 to September 2018 [16], a weighting factor for the individual models included in the synthetic EV-Mix was defined. Accordingly, the synthetic EV-Mix is an aggregation of all the mentioned EV charging patterns, whereby each pattern was weighted based on their model's weighting factor.

Consequently, an EV-Mix pattern was created, which represents a synthetic charging pattern of one electric vehicle based on the current EV sales situation. As a result, to the previously mentioned weightings, the synthetic EV mix includes the probability of a certain type of EV being connected to a charging station, whereby the determination of the effects of the electric mobility is improved. Figure 2 illustrates the process of the synthetical EV-Mix generation.

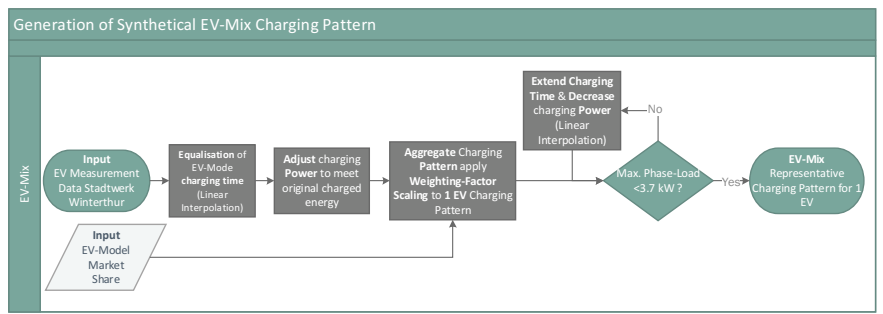

Fig. 2. Flowchart of Synthetical EV-Mix generation
Subsequently, Figure 3 presents the synthetical EV-Mix charging pattern with the customised level of charge not exceeding $3.7 \mathrm{~kW}$ per phase. In the case of symmetrical grid simulation, loads of each phase were combined in a total load, and distributed equally.

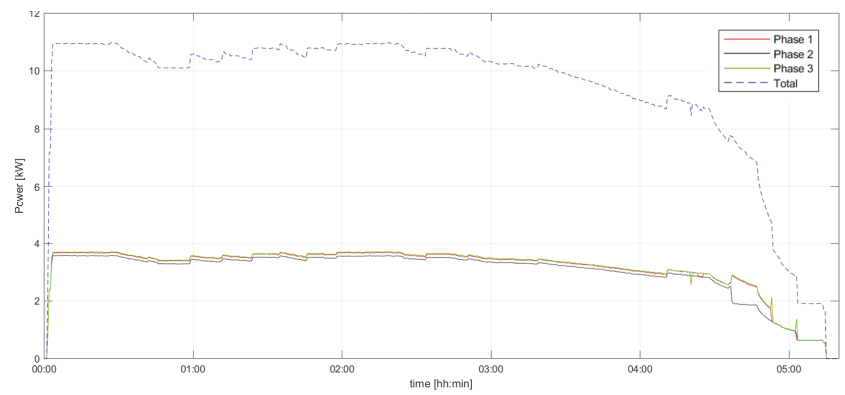

Fig. 3. EV Mix Charging Pattern three phased and combined load pattern

\section{Determination and Initialisation of the Charging Process}

In order to implement a more realistic EV charging situation in the QDS, a "Quasi-Random-Gaussian-based" determination of the EV charging initialisation was developed. The aim of this determination approach is to define a time frame, rather than a specific time, in which it is likely that an EV charging process is initialised. The applied Gaussian-curve within the algorithm leads to an increasing probability of a charging initialisation towards the middle of the time frame.

The sequence of the EV charging determination is presented in Figure 4. The required inputs for the determination are the following:

- Amount of EVs to be charged

- Consumer-based time frame in which a charging process is to be expected

- EV charging pattern

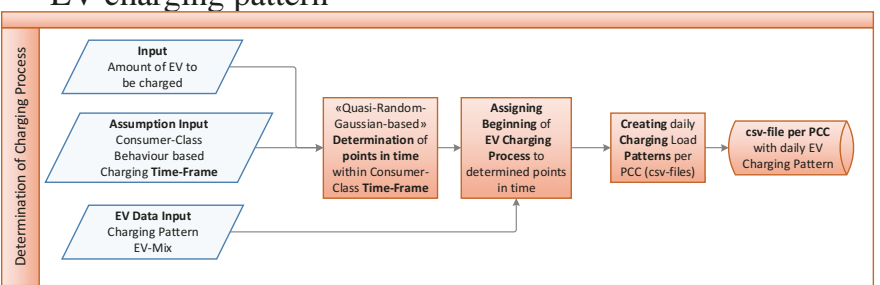

Fig. 4. Flowchart of the determination and initialisation of the EV charging process

As an example of the determination and initialisation of a charging process Figure 5 is presented. For this example, 3 EVs were defined to be charged within a time frame of 5-hours and furthermore, the symmetrical EV-Mix charging pattern was applied. Figure illustrates the Gaussian-curve representing the changing probability of an initialisation throughout the time frame. The time frame starts at 00:00 and ends at 05:00. A gradual increase of the total load during the time frame can be observed due to the subsequent initialising of the charging processes.

\section{E. Sequential Data and Simulation Processing}

In order to distribute the amount of EV charging stations within the grid and define the initialisation of the EV charging process, two algorithms were applied. The algorithm described in D "Determination and Initialisation of the Charging Process" was utilised in combination with an allocation-algorithm to realise the distribution of charging stations among the PCCs. 


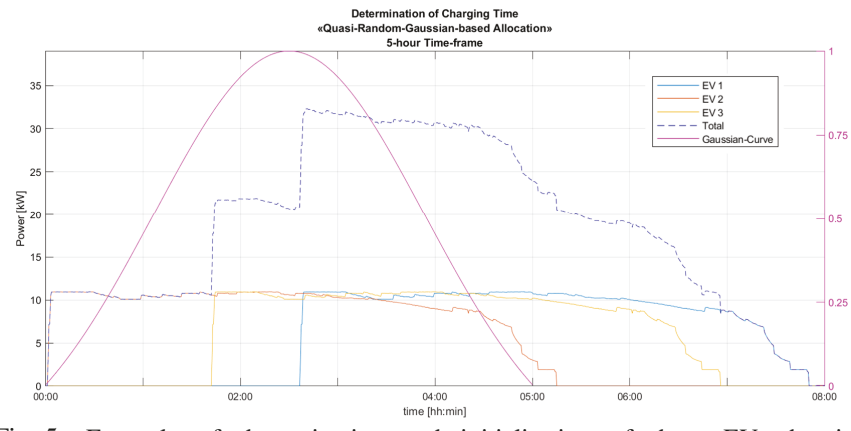

Fig. 5. Example of determination and initialisation of three EV charging processes on "Quasi-Random-Gaussian-based Allocation" in a 5-hour time frame
To further clarify, Figure 6 presents the sequential approach and the application of the mentioned algorithms. The input information for the sequential algorithm approach were distinguished between "Scenario Input", "Grid Input", "Assumption Input" and "EV Data Input". The Inputs are listed as follows:

- Scenario Input - EV share

- Grid Input - Number of total grid consumers

- Grid Input - max. charging station per PCC

- Grid Input - Weighting factor per commercial PCC

- Assumption Input - Charging time frame

- EV Data Input - EV-Mix charging pattern

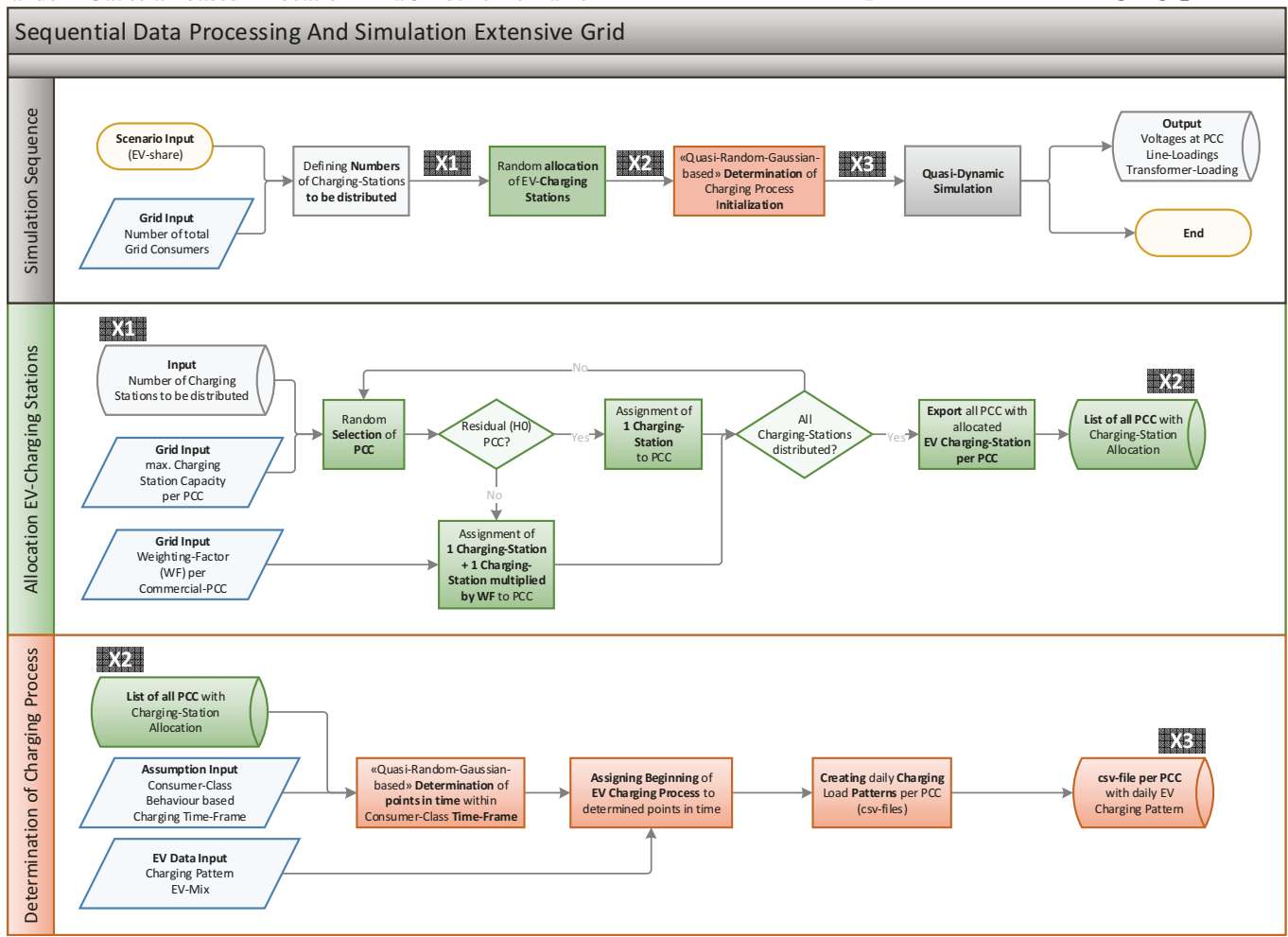

Fig. 6. Flowchart of Grid simulation and data processing

\section{EXTENSIVE GRID AND INPUT INFORMATION DEFINITION}

The following Figure 7 visualises the distinction made for the radial supplied feeders within the extensive SW grid. This distinction was realised to allow a more comprehensive investigation and feeder specific conclusion regarding limitation and EV share.

In order to perform time series simulations, all the consumers - respectively all the PCC - were assigned a SLP. The SLP class for every PCC was defined based on information presented by SW. Furthermore, 63 PCCs can be found within the extensive grid. Seven PCCs were presented in a simplified form, as loads directly supplied by the LVtransformer busbar. The $63 \mathrm{PCC}$ are roughly tabulated to their consumer class as shown in Table IV.

TABLE IV. EXTENSIVE GRID INFORMATION OF TOTAL PCC AND ENERGY

\begin{tabular}{|c|c|c|c|}
\hline $\begin{array}{c}\text { Consumer } \\
\text { Class }\end{array}$ & $\begin{array}{c}\text { Amount of PCC } \\
\text { per Consumer } \\
\text { class }\end{array}$ & $\begin{array}{c}\text { Amount of } \\
\text { Consumer } \\
\text { per PCC }\end{array}$ & $\begin{array}{c}\text { Total amount of } \\
\text { energy consumed } \\
\text { per consumer class }\end{array}$ \\
\hline Residential & 55 & 396 & $1303.9 \mathrm{MWh}$ \\
\hline Commercial & 7 & 46 & $5262 \mathrm{MWh}$ \\
\hline
\end{tabular}

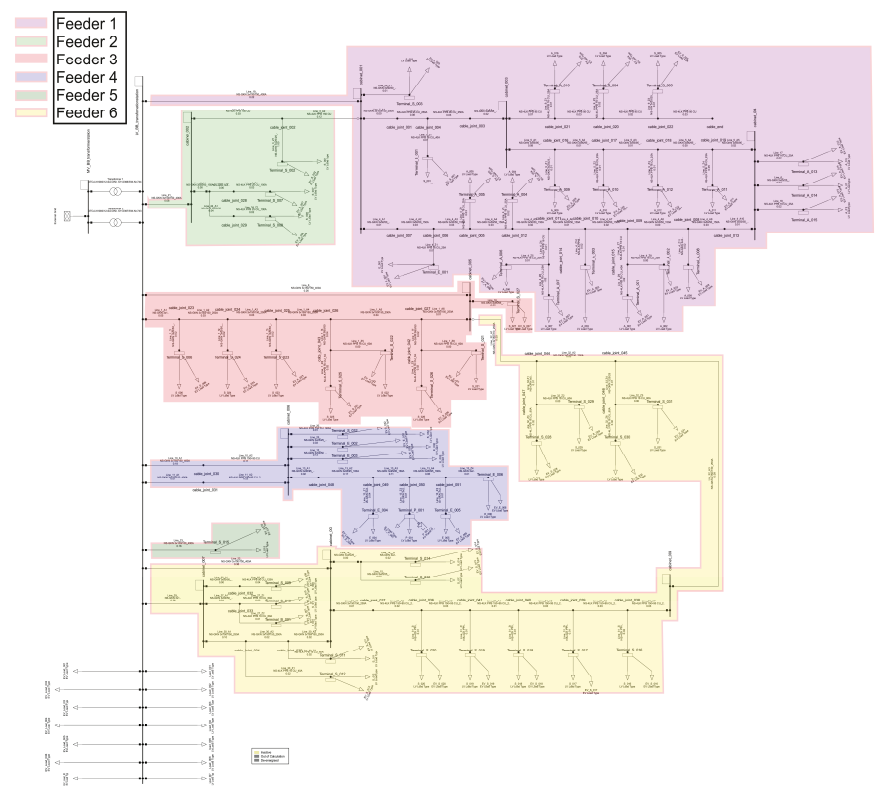

Fig. 7. SW Extensive Grid distinction of radial operated feeders 


\section{A. Definition of EV Charging Station to be Distributed}

As presented in Table IV, the amount of residential consumer within the extensive grid is set to 396. Consequently, the total amount of residential customers was considered as a plausible basis for the maximal possible EV-Charging stations to be installed among residential PCCs. Therefore, a $100 \% \mathrm{EV}$ share represents $396 \mathrm{EV}$ charging stations distributed among residential PCC.

A less evident approach was applied for the non-residential consumer such as commercial and agricultural consumer classes. Table V lists all the non-residential consumers with the maximum amount of charging stations considered at a $100 \%$ scenario. It should be noted that the assumed "100\%-amounts" of EV charging stations are not considered to represent a plausible scenario. It is purely set as a maximum - respectively basis - to determine the amount of EV charging stations to be deployed at a more realistic scenario.

TABLE V. DEFINITION OF NON-RESIDENTIAL EV CHARGING STATIONS AT $100 \%$ EV SHARE SCENARIO

\begin{tabular}{|c|c|c|c|c|}
\hline PCC & Type & Class & $\begin{array}{c}\text { Maximum amount } \\
\text { of EVs at 100\% } \\
\text { share scenario }\end{array}$ & Remarks \\
\hline E_002 & Mini golf & G0 & 5 & \\
\hline E_003 & campsite & G0 & 30 & \\
\hline E_004 & hut & G2 & 3 & $\begin{array}{c}\text { 100 charging } \\
\text { stations } \\
\text { represent 1/3 of } \\
\text { parking spaces. }\end{array}$ \\
\hline Load_001 & $\begin{array}{c}\text { shopping } \\
\text { centre }\end{array}$ & G4 & 100 & \\
\hline P_001 & hut & G6 & 3 & \\
\hline S_015 & $\begin{array}{c}\text { gas } \\
\text { station }\end{array}$ & G2 & 30 & \\
\hline S_032 & restaurant & G0 & 10 & \\
\hline & & total: & 183 & \\
\hline
\end{tabular}

Finally, Table VI presents the distributed amount of EV charging stations per consumer class and scenario. Furthermore, a limitation of EV charging stations per PCC was defined. The limit of EV charging stations per PCC is set equal to the number of consumers registered at a specific PCC.

TABLE VI. DISTRIBUTION OF EV CHARGING STATION PER SCENARIO AND

\begin{tabular}{|c|c|c|c|c|c|}
\hline Simulation Scenario & $\mathbf{8 \%}$ & $\mathbf{1 0 \%}$ & $\mathbf{1 2 \%}$ & $\mathbf{2 0 \%}$ & $\begin{array}{c}\text { Max possible EV Charging } \\
\text { Stations to distribute } \\
\text { (100\% Scenario) }\end{array}$ \\
\hline Residential (H0) & 32.2 & 40.2 & 48 & 79.8 & 396 \\
\hline $\begin{array}{c}\text { Non-Residential } \\
\text { (G0, L0 etc.) }\end{array}$ & 16.8 & 19.6 & 24.8 & 39.2 & 183 \\
\hline Sum & 49 & 59.8 & 72.8 & 119 & 579 \\
\hline Effective EV-Share & $8.5 \%$ & $10.3 \%$ & $12.6 \%$ & $20.6 \%$ & $100 \%$ \\
\hline
\end{tabular}

\section{B. Consumer Based EV Charging Time Frame}

For the extensive grid simulation, a consumer class respectively consumer specific - time frame was specified. Within this defined time frame, the possibility for an initialisation of an EV charging process is given. Consequently, no charging process can be initiated outside of the mentioned duration. Accordingly, Table VII and Table VIII present the time frames for the non-residual and residual PCC.
TABLE VII. DEFINITION OF NON-RESIDENTIAL CHARGING TIME FRAME AND MAXIMUM DEPLOYMENT OF EV CHARGING STATIONS AT 100\% EV SHARE

\begin{tabular}{|c|c|c|c|c|}
\hline PCC & $\begin{array}{c}\text { Beginning } \\
\text { time } \\
\text { frame } \\
\text { (morning) }\end{array}$ & $\begin{array}{c}\text { Ending } \\
\text { time } \\
\text { frame } \\
\text { (morning) }\end{array}$ & $\begin{array}{c}\text { Beginning } \\
\text { time frame } \\
\text { (afternoon) }\end{array}$ & $\begin{array}{c}\text { Ending } \\
\text { time frame } \\
\text { (afternoon) }\end{array}$ \\
\hline E_002 & $09: 00$ & $12: 00$ & $16: 00$ & $21: 00$ \\
\hline E_003 & $09: 00$ & $12: 00$ & $16: 00$ & $21: 00$ \\
\hline E_004 & $09: 00$ & $12: 00$ & $16: 00$ & $21: 00$ \\
\hline Load_001 & $08: 00$ & $12: 00$ & $15: 00$ & $20: 00$ \\
\hline P_001 & $09: 00$ & $12: 00$ & $16: 00$ & $21: 00$ \\
\hline S_015 & $10: 00$ & $13: 00$ & $18: 00$ & $23: 00$ \\
\hline S_032 & $09: 00$ & $12: 00$ & $16: 00$ & $21: 00$ \\
\hline
\end{tabular}

TABLE VIII. DEFINITION OF RESIDENTIAL PCC CHARGING TIME FRAME AND MAXIMUM DEPLOYMENT OF EV CHARGING STATIONS AT 100\% EV SHARE

\begin{tabular}{|c|c|c|c|}
\hline Load Class & $\begin{array}{c}\text { Beginning time } \\
\text { frame }\end{array}$ & $\begin{array}{c}\text { Ending time } \\
\text { frame }\end{array}$ & $\begin{array}{c}\text { Maximum amount of } \\
\text { EVs at 100\% EV } \\
\text { share scenario }\end{array}$ \\
\hline $\mathrm{H} 0$ & $16: 00$ & $21: 00$ & 396 \\
\hline
\end{tabular}

\section{RESULTS AND DISCUSSIONS}

In this chapter, the simulation results of the investigated "Extensive Grid" are outlined. It should be noted that the aim of simulations was to define a maximum utilisation rate regarding EV charging processes within the LVDG and discover possible limitation, respectively negative impacts on the grid.

\section{A. Extensive Grid}

In the following sections, the results of the QDS of the existing LVDG provided by SW are presented. The presented data and results are derived from 5 simulations where each simulation represents a potential calendrical year in 2019. The statistical data of voltage deviation and line loading derived from these 5 simulations were newly defined as 100 percent and therefore represented one reference-year. In this section, a grid impact overview for each EV share scenario is presented.

In Figure 8, the initial grid, without any electric vehicle charging, is visualised as a heatmap. Throughout the QDS only SLP were applied according to consumer specification and their yearly energy consumption. The colour of all the grid terminals and lines ranges between dark green and turquoise, which indicates, that the voltage deviation and loading was in acceptable limits.
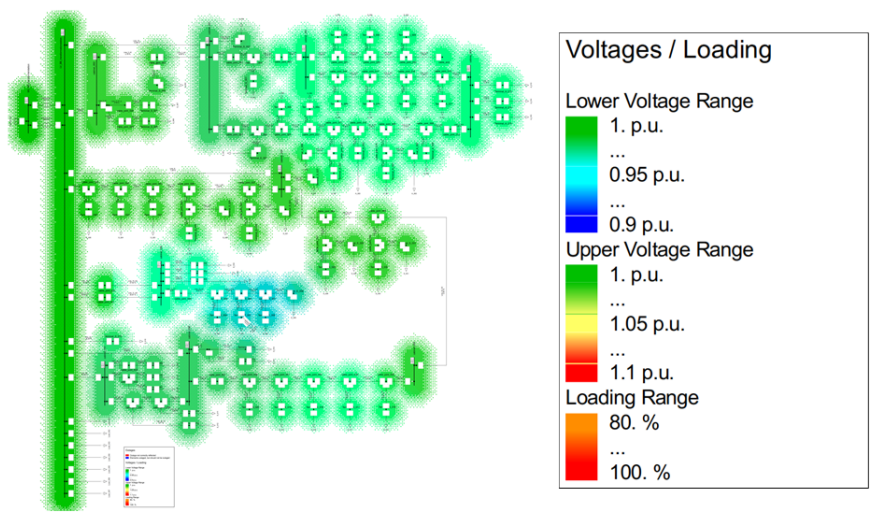

Fig. 8. Heatmap of initial SW extensive grid with $0 \% \mathrm{EV}$ share 
That the grid simulation was within limits defined by SW is proven with the statistical results shown in Figure 9 for the line loading and in Figure 10 for the voltage deviation. In detail, the major line loading of all the lines in the grid was below $30 \%$ for 98 percent of the year. Furthermore, the line with the highest loading throughout the year is Line 12 of Feeder 4, which reached the maximum of just below $70 \%$.
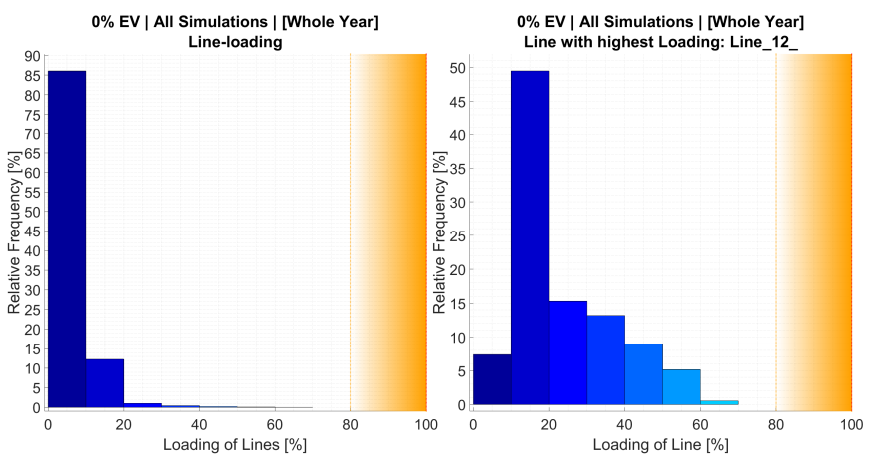

Fig. 9. Line-Loading distribution with $0 \% \mathrm{EV}$ share

Likewise, the voltage deviation of all the terminals in the grid was between 1.005 and 0.975 p.u. for 97 percent of the year. However, Terminal E003, which shows the lowest voltage deviation, was near 0.95 p.u. for 2 percent of the year approximately 7 days a year -, and therefore close to the limits set by SW. Also should be noted, that Terminal E003 represents a campsite which belongs to Feeder 4 and was simulated with a G0 SLP and an annual energy consumption of 123 '480 kWh.
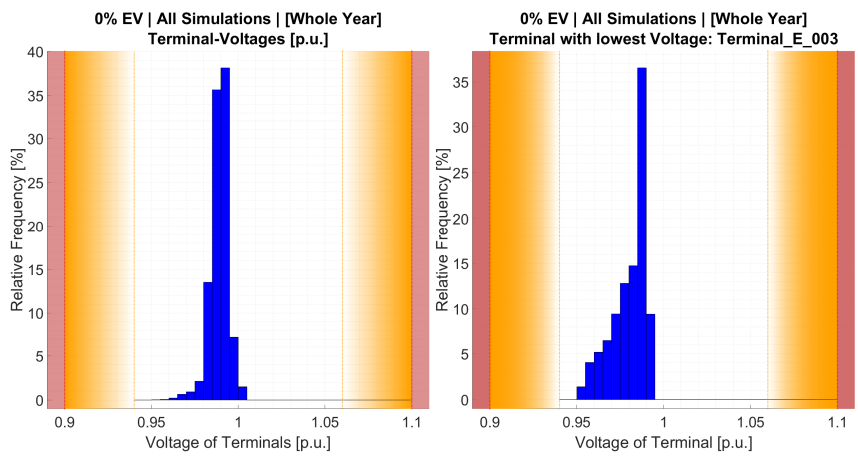

Fig. 10. Statistical Voltage deviation distribution with $0 \% \mathrm{EV}$ share

Further can be noted, that Terminal E003 is the PCC of Line 12, which highlights the correlation of voltage deviation and loading.

\section{B. $8 \%$ Scenario}

In Figure 11, the extensive grid, with an electric vehicle share of 8 percent, is visualised as heatmaps derived from the five QDS. For most simulations, the colour of the heatmap is still mainly between dark green and turquoise when compared to the initial grid. However, certain parts in the grid show a reddish colouring and darker blues, which indicates that the voltage deviation and loading at these points exceeded the limits.
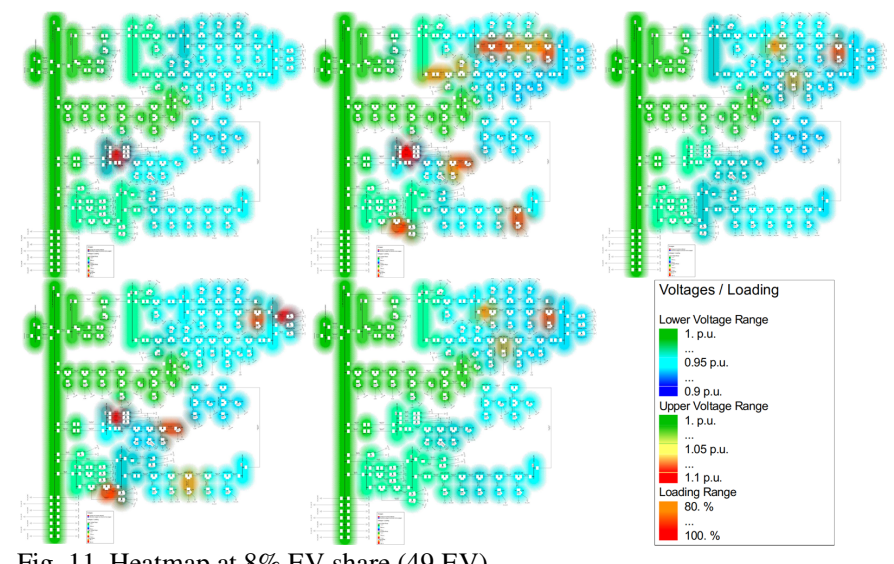

Fig. 11. Heatmap at $8 \% \mathrm{EV}$ share (49 EV)

The line loading statistics for all cables, which are derived from the reference-year data (5 Simulations), are visualised in Figure 12. In detail, 99.91 percent of the reference-year loading data are below $100 \%$ loading. The most loaded line - Line $25-$ exceeded $100 \%$ loading for 7.78 percent of the year, which is approximately 28 days. Line 25 is part of Feeder 4 and supplies Terminal E_002 - a minigolf facility - which had a maximum EV share of 6 charging stations in simulation 4 and an average EV charging station share of 2.4 throughout the reference-year.
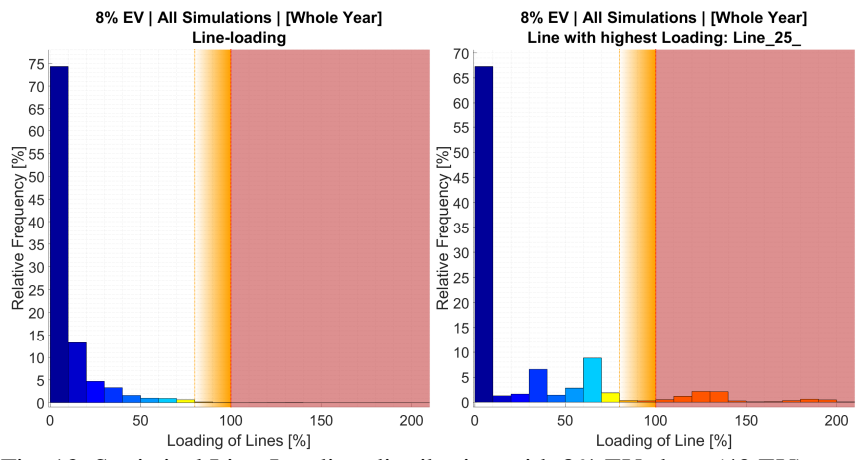

Fig. 12. Statistical Line-Loading distribution with $8 \% \mathrm{EV}$ share (49 EV)

Similarly, Figure 13 shows that the voltage deviation statistics for most terminals stayed within the SW limits, whereas Terminal S002 exceeded defined limits for 5.79 percent of the year (ca. 21 days). Terminal S002 belongs to Feeder 2 and represents a residential housing with one customer. Terminal S002 had a maximum EV charging station share of 1 during simulation $1 \& 2$ and an average EV charging station share of 0.4 throughout the reference-year.
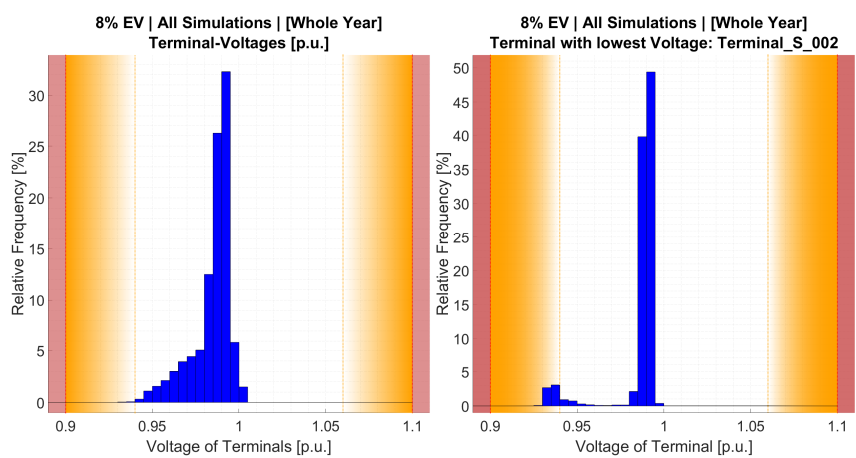

Fig. 13. Statistical Voltage deviation distribution with $8 \%$ EV share (49 EV) 
In review, only certain lines with a low current capacity, which are defined by their respective fuses, will need adjustment or replacement of their protection device. For example, the fuse on Line 25 has a six times lower load capacity than its cable specification. If certain fuse upscaling at the respective parts of the grid were possible to be implemented, the $8 \%$ scenario would appear to be feasible. Otherwise, the installation of charging stations must be regulated by $\mathrm{SW}$ at described places.

With attention to voltages, only an insignificant share of the grid and only for a short time of the year will the voltages exceed the limits of SW. Therefore, solely solutions for the few terminals with the lowest voltage should be considered.

Due to the random-nature of the distribution of EVs in the grid, the resulting share of each individual feeder, as presented in Table IX, is different to the overall $8 \% \mathrm{EV}$-share of the grid. To point out, Feeder 1 - a residential housing district - shows a relative EVs share of $32.9 \%$. Or throughout the five simulations an average 10.2 EV charging stations distributed among 31 consumers. Thus, in mentioned feeder, four times higher percentage is acceptable for the grid to still function normally. On the other hand, Feeder 4, which includes the line with the highest loading - Line 25 - does not tolerate the $15.2 \%$ relative share. Conversely, it is possible that the assumptions of the maximum EV-charging capabilities for the load at Line 25 were excessive, whereby, the line was predestined to overload.

TABLE IX. RELATIVE FEEDER SHARE AND NUMBER OF EV FOR THE 8\%

\begin{tabular}{|c|c|c|c|c|c|c|}
\cline { 2 - 7 } \multicolumn{1}{c|}{} & Feeder 1 & Feeder 2 & Feeder 3 & Feeder 4 & Feeder 5 & Feeder 6 \\
\hline Relative Share & $32.9 \%$ & $9.5 \%$ & $8.2 \%$ & $15.2 \%$ & $8 \%$ & $8.2 \%$ \\
\hline Avg.Nr. of EV & 10.2 & 2 & 4.6 & 8.2 & 2.4 & 11.6 \\
\hline
\end{tabular}

\section{C. $10 \%$ Scenario}

In comparison to the previous scenarios, the heatmaps of the $10 \%$ EV-share scenario (see Figure 14) show less green, more turquoise, a wider area of reddish and dark blue colouring. Consequently, even more lines and terminals exceed the limits.

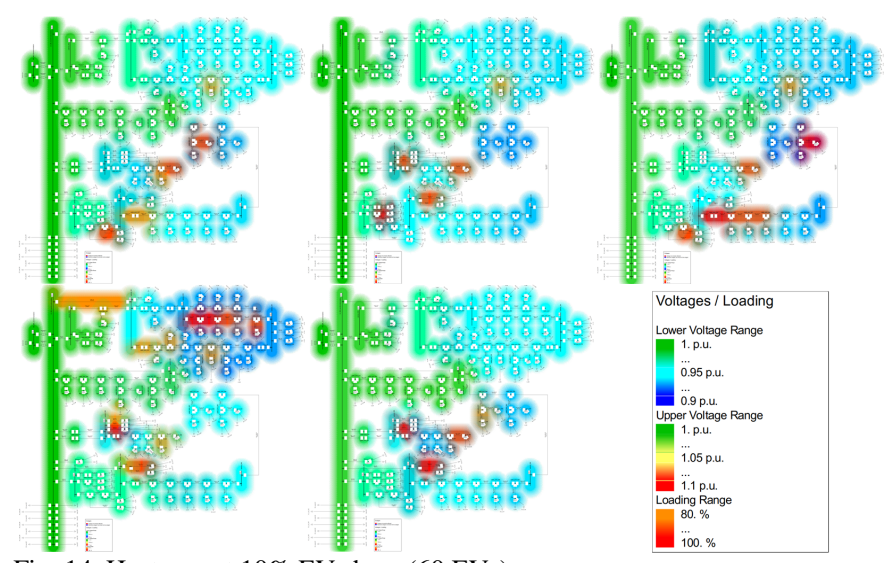

Fig. 14. Heatmap at $10 \%$ EV share (60 EVs)

The line loading data of the grid throughout the referenceyear is shown further in Figure 15, where it can be discerned that of all the simulation data 99.9 percent are below $100 \%$ loading, which is equivalent to the results of the $8 \%$ scenario. Conversely, the most loaded line - Line $14 \mathrm{a}$ - is exceeding $100 \%$ loading for 1.94 percent of the year (7 days), which is only accounting to one-fourth of the line with the highest loading of the $8 \%$ scenario. Line 14a is part of Feeder 6 and supplies Terminal S014 which had a maximum EV share of 3 charging stations in simulation 5 and an average EV share of 1.4 throughout the reference-year.

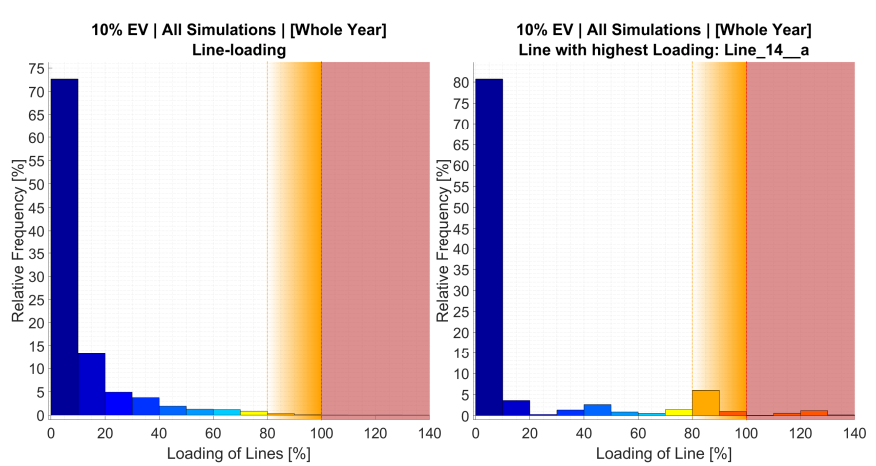

Fig. 15. Statistical Line-Loading distribution with 10\% EV share (60 EV)

In contrast to the loading, the statistics of the voltage deviation is visualised in Figure 16. Notably, the voltage of the terminals exceeded the SW limits in $1.21 \%$ of cases and in Terminal S028 in $6.73 \%$ of the year, which is close to 25 days. Terminal S028 is found in Feeder 6 and had a maximum EV share of 3 charging stations in simulation 5 with an average share of 1.4 EV throughout the reference-year.
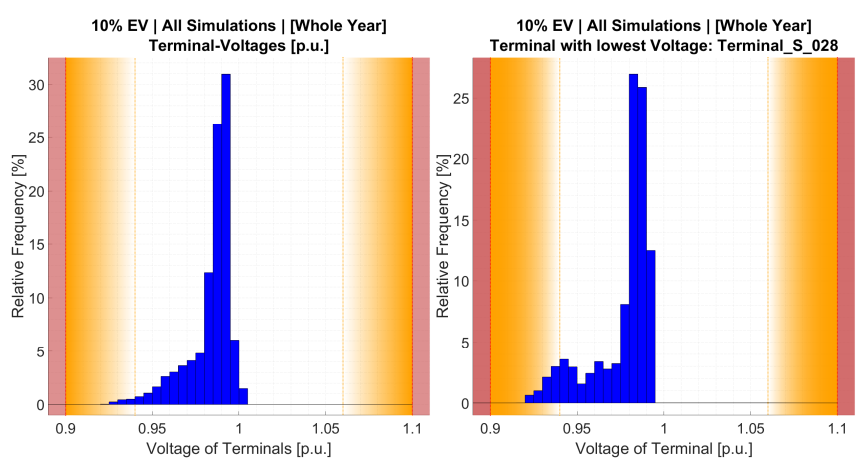

Fig. 16. Statistical Voltage deviation distribution with $10 \%$ EV share (60 EV)

In comparison to the 8 percent scenario, further lines will need an adjustment of their protection devices, respectively, an adjustment of the line load capacity while at the same time more terminals will exceed the lower limit of SW. However, with $60 \mathrm{EV}$ charging stations of $11 \mathrm{~kW}$, there will still be no impact on the functioning of the overall grid. The maximum transformer loading in Simulation remains on around $52.1 \%$.

In Table $\mathrm{X}$, the relative share of each feeder is presented. Similarly, to the $8 \%$ scenario, the relative share of the residential district - Feeder 1 - allows a higher share of EV without excessively exceeding the SW limitation. On the other hand, a district with industrialised apartment blocks - Feeder 4, which includes Terminal S028, shows overall lower voltage levels with only a relative share of $9.9 \%$.

TABLE $X . \quad$ RELATIVE FEEDER SHARE AND NUMBER OF EV FOR THE $10 \%$

\begin{tabular}{|c|c|c|c|c|c|c|}
\cline { 2 - 7 } \multicolumn{1}{c|}{} & Feeder 1 & Feeder 2 & Feeder 3 & Feeder 4 & Feeder 5 & Feeder 6 \\
\hline Relative Share & $36.8 \%$ & $13.3 \%$ & $11.1 \%$ & $22.2 \%$ & 10.7 & $9.9 \%$ \\
\hline Avg.Nr. of EV & 11.4 & 2.8 & 6.2 & 12 & 3.2 & 14 \\
\hline
\end{tabular}


D.

\section{$12 \%$ Scenario}

The heatmaps of the scenario with a $12 \% \mathrm{EV}$-share, which is visualised in Figure 17, show mostly a red and dark blue colouring. Thus, most lines and terminals have exceeded the limits at least once during the five simulations.
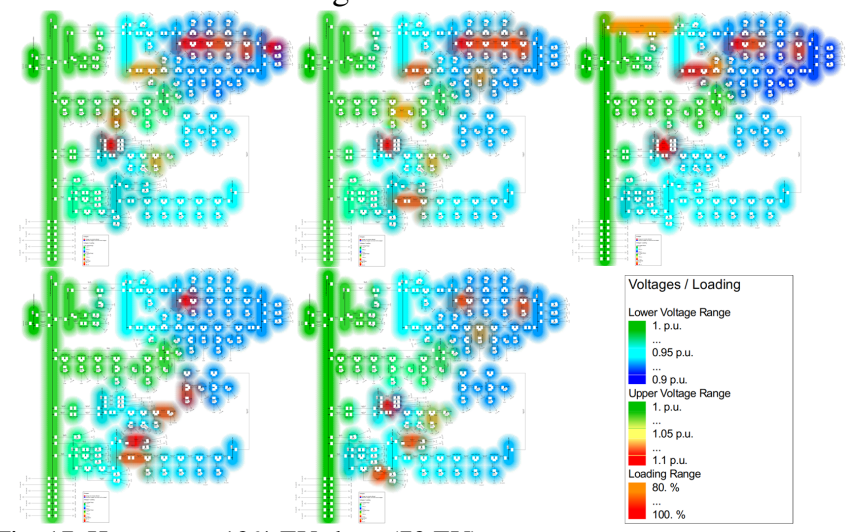

Fig. 17. Heatmap at $12 \% \mathrm{EV}$ share $(73 \mathrm{EV})$

Although, the reference-year statistics of the line loadings as seen in Figure 18- still shows an acceptable loading for $99 \%$ of cases, Line 25 exceeded the fuse capacity for 13.94 percent of the year - ca. 51 days. Line 25 is part of Feeder 4 and supplies Terminal E_002 - a minigolf facility, to which had a maximum EV share of 12 charging stations in simulation 5 and an average EV share of 2.8 throughout the reference-year.
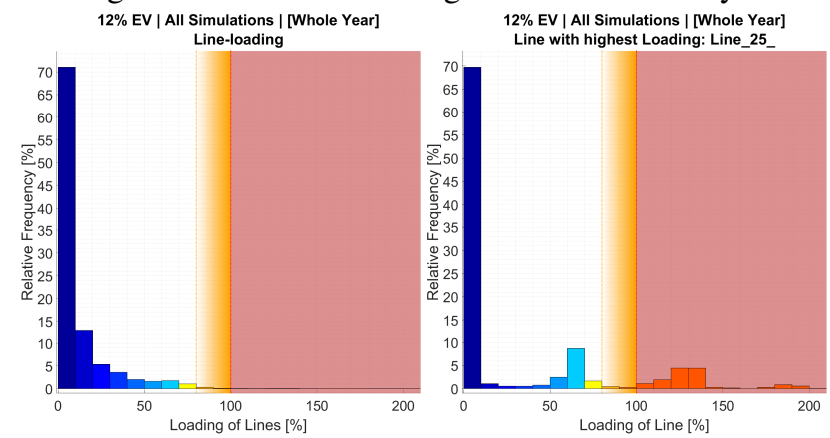

Fig. 18. Statistical Line-Loading distribution with $12 \%$ EV share (73 EV)

Moreover, the statistics of the voltage deviation in Figure 19 illustrates that in $3.11 \%$ of cases, the limit of SW was transcended. In addition, the voltage at Terminal A011 exceeded defined limit in 12.07 percent of the year - for 44 days and reached the lowest value of 0.916 p.u., which is close to the limit set by the EN 50160. Throughout the simulations, Terminal A011 had a maximum EV share of 1 charging station in simulation 1,2,3 and 5 with an average EV share of 0.8 charging stations throughout the reference-year.
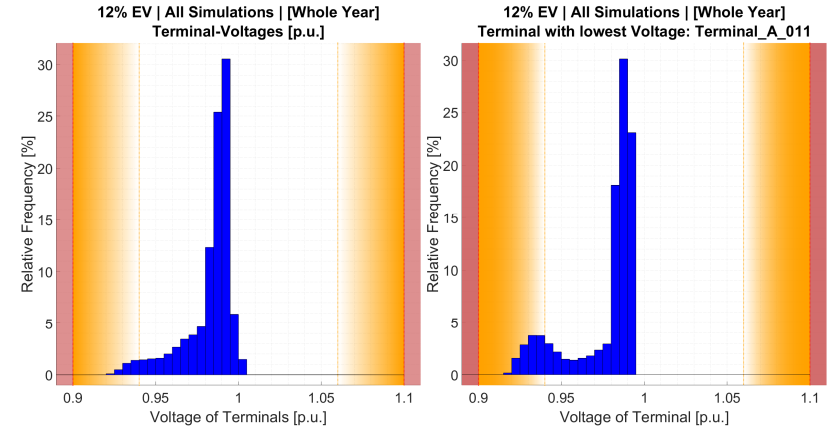

Fig. 19. Statistical Voltage deviation distribution with $12 \%$ EV share $(73 \mathrm{EV})$
Table XI present the number of EV of the relative feeder share, which have a strong impact on the previously analysed line loading and voltage values. In detail, Feeder 1, which includes the terminal with the lowest voltage - Terminal A011, resulted in a relative $\mathrm{EV}$ share of $47.7 \%$. Consequently, to fulfil the EN 50160 limits in all cases, 15 EVs can be identified as a maximum number of cars that can be charged at this Feeder 1. On the other hand, Feeder 1 includes the PCC for an apartment block, 17 detached houses and three-row homes for 2 families each. Accordingly, 15 cars are not disproportionate for the number of people, or respectively, 31 consumers registered in this neighbourhood.

TABLE XI. RELATIVE FEEDER SHARE AND NUMBER OF EV FOR THE $12 \%$

\begin{tabular}{|c|c|c|c|c|c|c|}
\cline { 2 - 7 } \multicolumn{1}{c|}{} & Feeder 1 & Feeder 2 & Feeder 3 & Feeder 4 & Feeder 5 & Feeder 6 \\
\hline Relative Share & $47.7 \%$ & $14.3 \%$ & $13.6 \%$ & $23.3 \%$ & $13.3 \%$ & $11.3 \%$ \\
\hline Avg.Nr. of EV & 14.8 & 3 & 7.6 & 12.6 & 4 & 16 \\
\hline
\end{tabular}

\section{E. $20 \%$ Scenario}

For the 20\% scenario the heatmaps in Figure 20 show deep red and dark blue colouring in most parts of the grid, which can be translated as the exceeding of the lower limitation set by EN 50160 and high overloading in many lines.

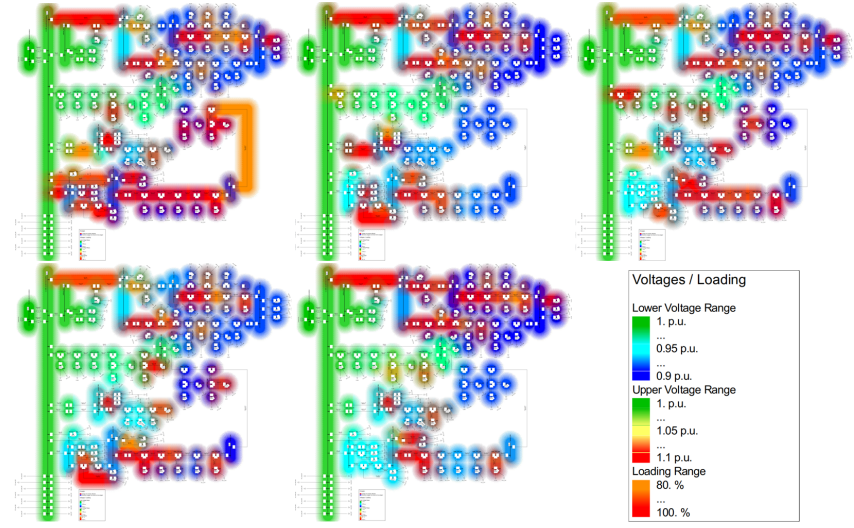

Fig. 20. Heatmap at $20 \%$ EV share (119 EV)

The line loading statistics of the grid, as seen in Figure 21, shows that $99 \%$ of cases are within acceptable limits, however, $1.47 \%$ are between 80 and 100 percent loading. Furthermore, the line with the highest loading - Line 12 - shows significantly high loading for most of the year. In detail, $100 \%$ loading was reached or exceeded for 11.76 percent of the year - close to 43 days. Line 12 supplies Terminal E003 which represents a campsite and had a maximum share of $18 \mathrm{EVs}$ in Simulation 2 with an average EV share of 9.6 charging stations throughout the reference-year.
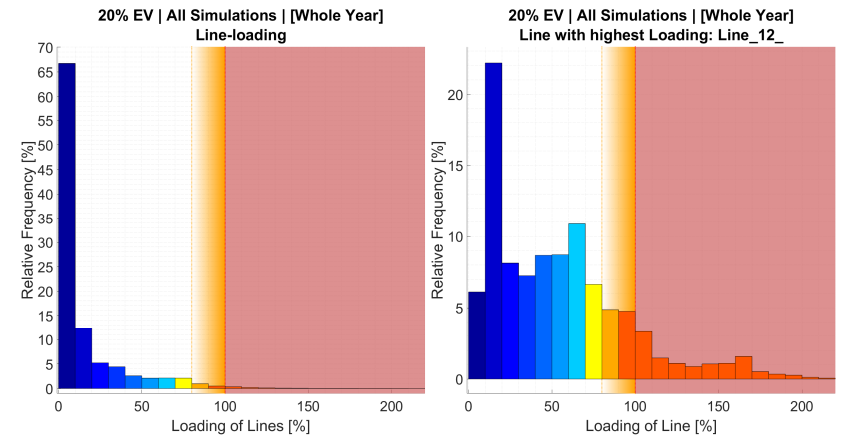

Fig. 21. Statistical Line-Loading distribution with 20\% EV share (119 EV) 
Correspondingly, the voltage deviation statistics highlights the overall decrease of voltage throughout the year (see Figure 22). More specifically, the voltage exceeded the SW limitation in $8.24 \%$ of cases and the EN 50160 in $0.45 \%$. Expressively, the voltage in Terminal S030 shows the violation of the EN 50160 limit for $3.05 \%$ of the year - around 11 days and the lowest value of 0.85 per unit. Terminal S030 is found at the remote end of Feeder 6 and was equipped with a maximum share of $3 \mathrm{EV}$ charging stations in Simulation 1 and an average EV share of 1.4 charging stations throughout the reference-year.
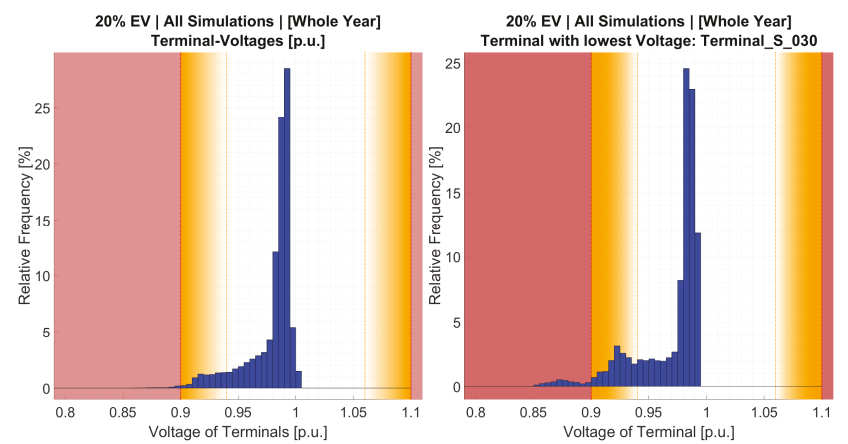

Fig. 22. Statistical Voltage deviation distribution with $20 \% \mathrm{EV}$ share (119EV)

The relative EV share of Feeder 6 , which includes the Terminal S030, is near to the $20 \%$ scenario share (see Table XII). In detail, the share of Feeder 6 represents $29 \mathrm{EV}$ charging stations, which result in the exceeding of the EN 50160 limit at particular terminals. Similarly, Feder 1 also violates the mentioned limits, which complies with the previously presented heatmaps. Markedly, only Feeder 3 and Feeder 5 remain within SW limitations in all cases. In essence, every feeder specific relative EV share and the averagely deployed EV charging stations throughout the $20 \%$ scenario are presented in Table XII. It is evident that the $20 \%$ scenario share exceeds the SW limitations. Furthermore, in accordance with the EN 50160 and the maximum voltage deviation, the grid capacity at an EV share of $20 \%$ - 119 charging stations at $11 \mathrm{~kW}$ - is reached. Accordingly, to define a more accurate margin of how many EV charging stations are feasible within the LVDG - complying with the EN 50160 - more simulations and scenarios between 12 and $20 \%$ are required.

TABLE XII. RELATIVE FEEDER SHARE AND NUMBER OF EV FOR THE $20 \%$

\begin{tabular}{|l|c|c|c|c|c|c|}
\cline { 2 - 7 } \multicolumn{1}{c|}{} & Feeder 1 & Feeder 2 & Feeder 3 & Feeder 4 & Feeder 5 & Feeder 6 \\
\hline Relative Share & $65.8 \%$ & $15.2 \%$ & $27.1 \%$ & $42.2 \%$ & $21.3 \%$ & $20.6 \%$ \\
\hline Avg.Nr. of EV & 20.4 & 3.2 & 15.2 & 22.8 & 6.4 & 29 \\
\hline
\end{tabular}

\section{F. Evaluation of the Extensive Grid's Resilience}

In conclusion, it can be determined, which of the scenarios are within the limitations and therefore in an acceptable voltage and loading range. In detail, to make a safe statement, the results of the grid simulations were used for the creation of boxplots (see Figure 23 and Figure 24), which were further defined for 01- and 99-percentil respectively. Consequently, the range of $99 \%$ percent of the results was assumed as an acceptable indicator for the feasibility of a scenario.

- Voltages: In Figure 23, the voltage ranges of the four scenarios from 8 to $20 \%$ are visualised. Essentially, the grid allows the $8 \%$ scenario with 49 electric vehicle charging stations at $11 \mathrm{~kW}$, whereas the $10 \%$ scenario with 60 electric vehicles barely exceeds the SW limits of a voltage of 0.94 per unit. While the feasibility of the $10 \%$ scenario for SW is debatable, the $12 \%$ scenario with 73 electric vehicles certainly violates the mentioned limitation. Furthermore, the $20 \%$ scenario does not exceed the EN 50160 limit, a voltage of 0.9 p.u., in $99 \%$ of cases. Nonetheless, a few values seem to reach values as low as 0.85 p.u., which would require certain adjustments or reinforcement at specific parts of the grid.

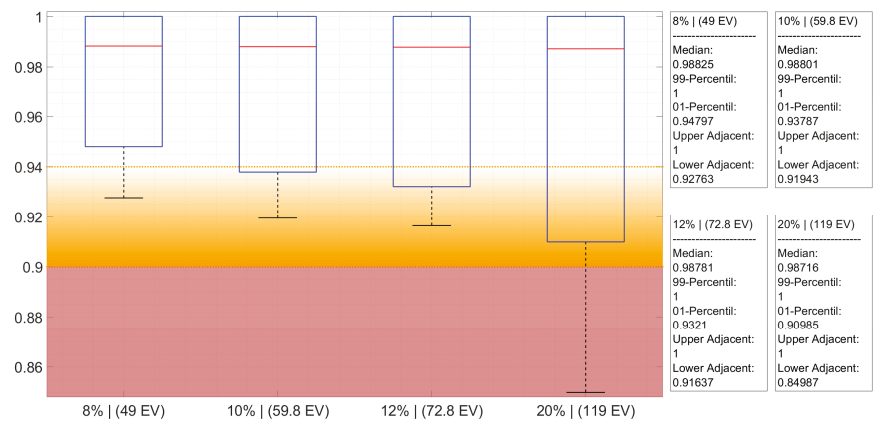

Fig. 23. Voltage statistics of the grid for four scenarios (each 5 simulations) with a box definition of 01-/ 99-percentile (includes colouring of the limitations of SW and EN 50160 standard)

- Line loading (fuse capacity): In Figure 24, the line loadings of the grid for the four scenarios are presented. As shown below, the lines of the grid will tolerate the number of $\mathrm{EV}$ for the 8, 10 and $12 \%$ scenario in $99 \%$ of cases. Additionally, the median values of the mentioned scenarios are low, with a mean value of ca. $5.5 \%$, which is due to the reason that there is only small electrical energy consumption and no EV charging at early mornings in the simulation. Concerning the loading of the grid specifically, the highest feasible share of electric vehicles can be identified in the 20\% scenario with 119 EV charging stations at $11 \mathrm{~kW}$. In further detail, the $99^{\text {th }}$ percentile value lies at 96.95 percent loading. On the other hand, an overloading of cables would already occur at certain lines where charging processes coincide. Accordingly, these parts of the grid would need reinforcement or at least a replacement of protection devices if such option is viable at the corresponding parts of the distribution network.

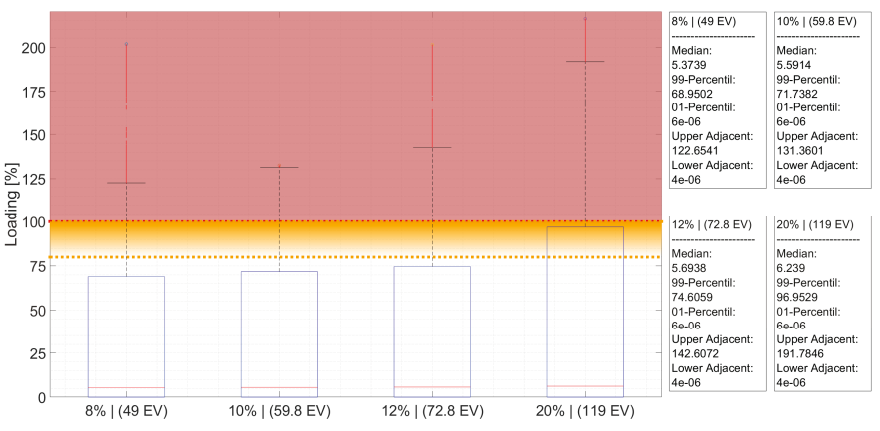

Fig. 24. Line loading statistics of the grid for four scenarios (each 5 simulations) with a box definition of $01 / 99$ th percentile

- Transformer loading capacity: The transformer loading limitations were identified with the $60 \%$ scenario. Therefore, if 360 charging stations at $11 \mathrm{~kW}$ were installed within the grid, the transformers would reach their maximum capacity. However, in cases when more charging processes overlapped, a lower number of EV would suffice. 
- Weak-Links of the grid: For the practical evaluation of the grid, Feeder 1 and 6 were identified as the weakest parts of the grid, both loading- and voltage-wise. The cable connection to loads with a low protective device capacity (25A) shows overloading even with only $1 \mathrm{EV}$ connected. Consequently, at least 15 lines in Feeder 1 would need adjustment to the mentioned devices, if a wide installation of charging stations is expected. Likewise, in Feeder 6, 8 cables fuses with a capacity of 40 to $60 \mathrm{~A}$ would need to be replaced with a total EV share of $10 \%$ (or more than one EV charging at the respective PCC). However, with a share of more than $12 \%$ ( $\geq 3$ EV charging), at the mentioned location would require a line reinforcement in addition to the fuse upscaling. Although Feeder 4 shows overloading and high voltage deviation with an EV share of more than $10 \%$, the problematic line was overcharged due to an exaggerated maximal EV share at this PCC and therefore, may be less critical than visualised in the simulation results. Additionally, since Feeder 1 and 6 consist of long cable connections, the outermost terminals already show a violation of SW with $8 \%$ (0.93 p.u.) and critical voltage levels for EN 50160 limits with $12 \%$ (0.916 p.u.). Consequently, these feeders should be reinforced in the near future.

\section{CONCLUSION}

The work and its simulations were executed based on veridical data. These were in detail the EV charging measurements, the EV model share on the Swiss market and the distribution grid layout with its component specification (e.g. transformer, cables, and fuse capacities). Similarly, the assumption of the maximum number of charging stations at each load was based on the number of consumers (one station per consumer) at the respective location, and thereby, a conservative but realistic definition was created. Likewise, with the focus on $11 \mathrm{~kW}$ charging stations, which presents a broad technical availability and therefore its higher probability to be installed at customers' homes, further convergence with realworld situations were achieved. Additionally, due to the simplification of the charging process, whereby the possibility of a DoD between $1 \%$ and $99 \%$ was neglected, the simulation represents a worst-case condition, and thus, the statements of the maximum number of $\mathrm{EV}$ includes an essential safety margin. Method-wise, the usage of the quasi-static time series simulation, allows the simulation with seasonal and daily changes, whereby critical conditions throughout the year were identified. Equally important, the usage of random allocation of charging stations in the LVDG and the quasi-random Gaussianbased distribution of charging times increases the realism of the results presented in this paper.

The results of the paper have provided insight into the EV charging capabilities of an existing LVDG. Evidently, in $99 \%$ of cases in the extensive LVDG, even a low share of symmetrical EV charging will lead to limitations being violated $(\geq 10 \%$ SW and $>20 \%$ EN 50160), whereby if single-phase charging occurs, the boundaries are exceeded even sooner, and aggregated charging could become more critical. In essence, and independent of the way of charging, an overlap of charging cycles - aggregation of loading - results in the most significant threat to the feasibility of EV charging infrastructure installations. For this reason, in consecutive works of the superordinate project, possibilities for the smart shifting of EV charging times should be analysed and the respective advantages determined.

\section{ACKNOWLEDGMENT}

This research is part of the activities of the Swiss Centre for Competence in Energy Research on the Future Swiss Electrical Infrastructure (SCCER-FURIES), which is financially supported by the Swiss Innovation Agency (Innosuisse SCCER program)

\section{REFERENCES}

[1] A. Wentworth, "All countries in the Paris Agreement now have policies to fight climate change," climateaction.org, 2018.

[2] European Commission, "Transport 2050: Commission outlines ambitious plan to increase mobility and reduce emissions," Press Release, 2018.

[3] M. Bürgi and B. Heiniger, "3,3 Prozent der neuen Autos fahren elektrisch," Handelszeitung, Zurich, 04-Mar-2019.

[4] Ernst Basler + Partner, "Szenarien der Elektromobilität in der Schweiz Update 2018," EBP-Hintergrundbericht, p. 31, 2018.

[5] E. Behrmann and C. Rauwald, "VW Cranks Up Electric-Car Plants to Overtake Tesla's Capacity,” Bloomberg.com, New York, 14-May-2019.

[6] International Energy Agency (IEA) and OECD, "Global EV Outlook 2018," 2018.

[7] H. Saele and I. Petersen, "Electric vehicles in Norway and the potential for demand response," Proc. - 2018 53rd Int. Univ. Power Eng. Conf. UPEC 2018, pp. 1-6, 2018.

[8] T. Fritz, A. Perry, A. Ranjan, J. Staeglich, and C. Underwood, "As More EVs Hit The Road, Blackouts Become Likely,” Forbes, 15-May-2019.

[9] D. Fischer, A. Harbrecht, A. Surmann, and R. McKenna, "Electric vehicles' impacts on residential electric local profiles - A stochastic modelling approach considering socio-economic, behavioural and spatial factors," Appl. Energy, vol. 233-234, no. May 2018, pp. 644-658, 2019.

[10] Stadtwerk Winterthur, "Main Page, Stadtwerk Winterthur," 2019. Available: https://stadtwerk.winterthur.ch/

[11] European Committee for Electrotechnical Standardization (CENELEC), "Voltage Characteristics in Public Distribution Systems, EN 50160," 1994.

[12] G. Bartak, H. Holenstein, and J. Meyer, Eds., " $D-A-C H-C Z$ Technical Rules for the Assessment of Network Disturbances", 2nd Edition. VEÖ, VSE, CSRES, VDN, 2007.

[13] H. Meier, C. Fünfgeld, T. Adam, and B. Schieferdecker, "Repräsentative VDEW Lastprofile," Forschungsbericht Brandenbur gische Technische Universität Cottbus, Lehrstuhl Energiewirtschaft, Eigenverlag VDEW. Frankfurt am Main 1999.

[14] BDEW Standardlastprofile Strom, Available: https://www.bdew.de/energie/standardlastprofile-strom/

[15] S. Habib, "A Comprehensive Study of Implemented International Standards, Technical Challenges, Impacts and Prospects for Electric Vehicles," IEEE Access, vol. 6, no. March, 2018.

[16] AutoSwiss, "Autoverkäufe nach Modellen: Modellstatistik 2018 / 2017." auto-schweiz (Vereinigung Schweizer Automobil-Importeure), 2018

Artjoms Obushevs received the BSc, MSc, Ph.D. degree in electrical engineering from the Riga Technical University, in 2008, 2010 and 2014 respectively. He is currently a Research Associate in Electric Power Systems and Smart Grids group at the Institute of Energy Systems and Fluid Engineering (IEFE) of the Zurich University of Applied Science ZHAW. His main research is focused on methods of mathematical modelling of electrical networks and systems elements; development of power systems planning; dynamic optimization methods and decision systems. 